\title{
Assessment of Geodynamical Stability of Mine Workings in Rock Ore
}

\section{Olga Vladimirovna Trushko and Dmitriy Aleksandrovich Potemkin}

\author{
The National Mineral Resources University (The Mining University), \\ Russia, 199106, Saint Petersburg, 21-st Line V.O., 2
}

DOI: http://dx.doi.org/10.13005/bbra/1984

(Received: 01 October 2015; accepted: 06 November 2015)

\begin{abstract}
This paper studied the global methods to determine the geodynamical stability of mine workings in the conditions of dynamic forms of rock pressure during the development of deep horizons of mines. It was found that the available approaches to the assessment of stability and classification of rock outcropping require further development as they do not give quantity assessment of rock fragmentation at all stages of deformation near mine workings and do not account for mechanics of rocks during dynamic impact and the ability to control mechanical processes in rock mass at before- and over-limit deformation stages. On the basis of experimental research done at Russian mines of OAO Sevuralboksitruda it was found that the nature of rock fragmentation in the border zone depends on the parameters of seismic waves which are in turn caused by the energy of the dynamic effects. Energy classification of dynamic effects was developed, most fully disclosing the nature of dynamic impact on mine workings, improved strength criterion was offered and operational condition of mine workings was determined.
\end{abstract}

Key words: Mine, mine workings, bump hazardous deposits, dynamic effects, stability criterion, rock ore, assessment of stability, seismic waves.

Worsening mining conditions after the beginning of developing deep horizons, the emergence of dynamic forms of rock pressure requires more efficient forms to ensure stability of workings and first of all, the development of assessment methodology. The current regulations [1] provide for, as the criterion for the assessment of rock ore stability, the shearing on cross-section outline during the service life without support, i.e., unfixed. Depending on the value of shearing expected (u), four categories of rocks stability are specified in Table 1.

\footnotetext{
* To whom all correspondence should be addressed.
}

Such an approach to the assessment of stability of mine workings in a few bump hazardous ore deposits is not applicable as the destruction of rocks near workings is brittle and begins upon the shearing of working's contour for a few millimeters only. It was experimentally proved that destruction zone in working's contour begins as the result of rock ore's transition into limit and even over-limit states due to growing non-uniform compression with summary effect of static and dynamic components. Meantime, ruptures are developed in rock ore, parallel to mine working's contour and in certain circumstances heavy destruction of rocks may occur. The intensity of those processes is greatly affected by over-limit stage of rocks fragmentation [2-4]. 
As field survey showed, the intensity of destruction in surrounding rock ore is determined by strength and endurance characteristics of the rock mass, its jointing level, working's orientation regarding the direction of maximal stress and dynamic effects parameters.

Therefore, for the prognostication and assessment of rock ore near mine workings under the conditions of dynamic rock pressure, the most suitable criterion should be based on the elastic model accounting for actual specifics of rocks destruction at all the stages of fragmentation including over-limit.

\section{METHODOLOGY}

\section{Analysis of existing methodologies}

There are a few existing methods to find geodynamical stability of mine workings [5-8].

Analytical and experimental computational method

A rather simple but quite fully reflecting the quality view of the phenomenon, mechanism of interaction between rocks and supports was taken as the basis of analytical and experimental computational method.

The origin of all occurrences of rock pressure is the stress of rock masses on the contour of mine workings and near. Meantime, rocks may be moving within elastic limits or by forming a zone of rocks in the stage of non-elastic deformation around mine workings (destruction or viscoplastic strain).

In the first case, deformations occur immediately after mining, and supports do not actually take them up. In the second case, working's contour shearing related to non-elastic deformation zone creates load on supports which cannot be prevented by the existing rigid supports causing their destruction.

An English scientist C. Emery offers to create the artificial zone of non-elastic deformations around mine workings releasing the load on support [8].

The growth of non-elastic deformations zone in the event of sufficient response of the support finally stops. It is explained by the growing radial component of rocks stress (first, being rather small equal to support's response, i.e., 0.1-0.5 MPa) as the non-elastic deformation zone grows. As a result, a moment comes when normal stress values on the elementary parallelepiped sites located at the boundary of elastic and non-elastic zones are becoming the values of the same order.

Thus, as non-elastic deformations zone is formed, the response of the system - support and floating shell of rocks around mine working grows and the rocks around working come to the state of equilibrium. Further contour's shearing and related growth of load on support terminate.

Little shifts of the contour may last for some time after visible stabilization. To develop the analytical experimental computational method, the methods of theory of dimensions, continuum mechanics, mathematical statistics and results of mine's instrumental monitoring were applied.

The quality view of the phenomenon is taken as the basis of calculations and confirmed by modelling using equivalent materials.

Rocks stress around workings is predetermined by the weight of overlying rock thickness $-g H$, where $g$ - volumetric weight of rocks, $H$ - working's depth from surface. The shearing prevention factors are strength of rocks $R$ and support's resistance $q$. Besides, the contour shearing $u$ will depend on the modulus of elasticity of rocks $\AA$ and the size of mine working: width $a ̀$ and height $h$.

In general view, the dependency may be written as follows:

$$
u=f(\gamma H ; R ; q ; E ; a ; h)
$$

\section{Probability statistical computational method}

Top rocks and floor shearing is affected by a great number of mining engineering and geological factors. Many of them are incidental and vary greatly in time and space. In the event of many sets of measuring the strength of rocks, the results of separate measurements will differ. In the same mine working, rocks properties will not be constant as well as dimensions of sections along working's length. Structure and thickness of rock layers in the ground and roofing, support's resistance, backfilling density, etc. are also incidental.

If a large number of workings are studied, the factors like support's material, form of working, method of mining are also incidental.

In this connection, the shearing of working's contour is the effect of a number of reasons which may be monitored but may not be calculated exactly. Taken together, those reasons 
allow to use probability methods accounting for incidental character of the emerging factors and incomplete information about the phenomenon's nature.

The monitoring over workings' stability in mines shows that all the factors affecting workings' roof and floor stability are changing within a specific range. In that range, the values of the said factors are distributed under a certain law described by the distribution curve. The research shows that the distribution of strength of rocks at simple compression, depths of workings, their cross-sections, thickness of the same rocks in roof/ floor, etc. are described by the normal distribution curve. In this case the probability that some incidental variable õ is within à $<\mathrm{x}<\mathrm{b}$ range, is equal to the surface area under the distribution curve between ordinates $a$ and $b$ and characterizes the density of distribution of such variable within that range.

Task assignment on prognostication of working's contour shearing

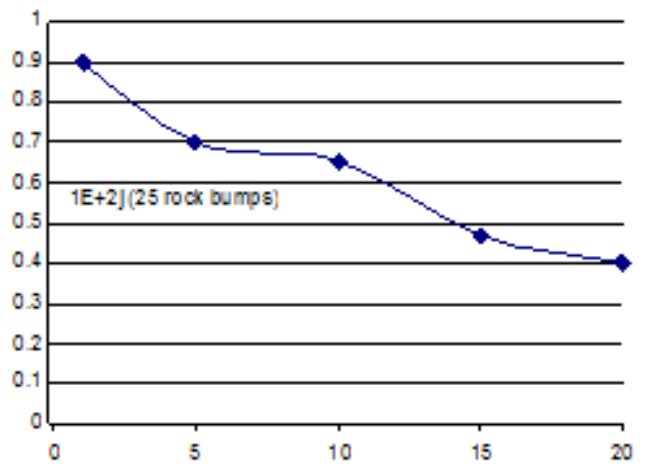

Knowing the law and the parameters of the distribution curve for each factor as well as the range of its changes, the latter may be divided into parts called characteristics.

The task on prognostication of working's contour shearing may be worded as follows: knowing the data about roof/floor shearing in a large number of workings characterized by a set of factors, to determine the contour shearing or its interval, based on known factors describing its state. On the basis of the probability approach the task may be worded as the task to find the probability of that range of shearing by a given set of characteristics if characteristics are known for each interval. $P_{\mathrm{ij}}$ values (characteristic's probability) are the probabilities of certain characteristics for each shearing interval. Knowing the law and the parameters of distribution of factors' values and dividing their ranges into characteristics, $\bigoplus_{\mathrm{ij}}$ may be found for each interval of shearing.

Having the initial data observed in mines, shearing interval may be prognosticated for

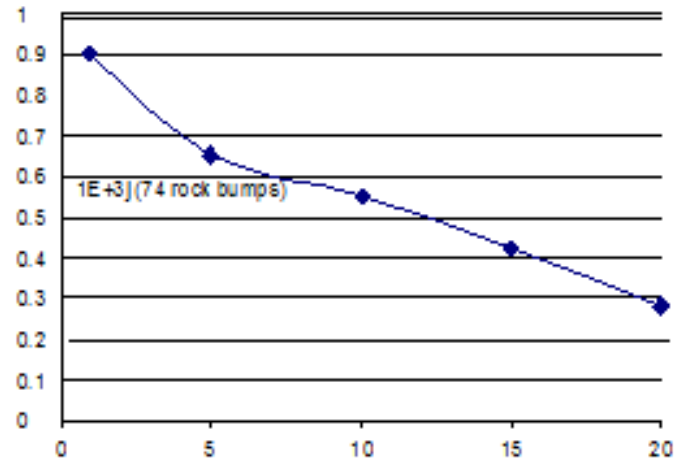

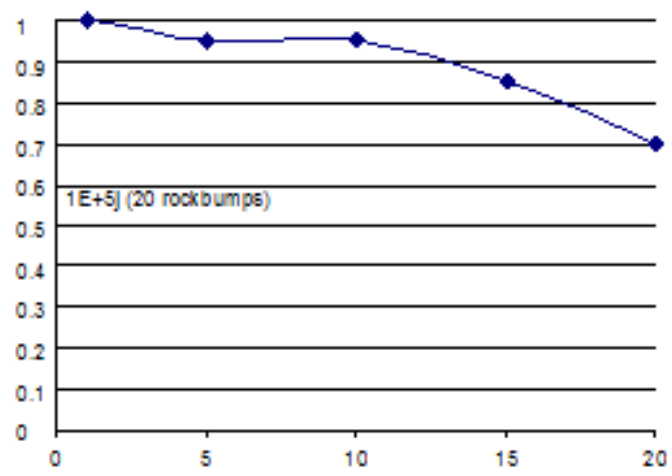

Fig. 1. Prognostication probability depending on isoline value 
workings' roof and floor with known characteristics in compliance with the geological survey and mining project.

The probability of working's contour getting into $\mathrm{j}$ interval by the value of shearing is determined by Bayes formula:

$$
P_{i}=\frac{P\left(u_{i}\right) \prod_{i=1}^{n} P_{i j}}{\sum_{j=1}^{m} P\left(u_{j}\right) \prod_{i=1}^{n} P_{i j}}
$$

where $Đ\left(u_{j}\right)$ - a priori probability of getting into $\mathrm{j}$ interval; $\bigoplus_{\mathrm{ij}}-$ known from the experience probability of $S_{i}$ characteristic at shearing interval $u_{i}$.

If the distribution of a priori probability for $\mathrm{u}$ is not known, then, suggesting that all shearing intervals are equally probable, Bayes formula may be written as follows:

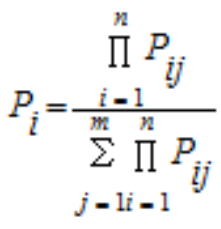

So, the formula (3) is used to determine the probability of working's contour getting in each interval of shearing. Finally, the interval of shearing is found by the maximal value of $\mathrm{P}_{\mathrm{i}}$.

The analysis of approaches to mine workings stability allows to conclude that the most widely distributed existing classification for rock mass with brittle nature of destruction is the dimensionless criterion $\mathrm{K}=\mathrm{gH} / \mathrm{R}_{\mathrm{cs}}$ corresponding to crack initiation in walls of the working and based on comparing maximal values of stress in the elastic model with the strength of rock mass. Its numeric values were obtained as a result of statistical data processing of mine field observations over rock pressure in deep workings of the central Donetsk

Table 1. Rocks stability categories depending on expected shearing value

\begin{tabular}{lcccc}
\hline $\begin{array}{l}\text { Stability } \\
\text { category }\end{array}$ & $\begin{array}{c}\text { Assessment of } \\
\text { rock stability }\end{array}$ & sedimentary & $\begin{array}{c}\text { Shearing in rocks } u, \mathrm{~mm} \\
\text { effusive }\end{array}$ & saliferous \\
\hline I & stable & under 50 & under 20 & under 200 \\
II & average stable & over $50-200$ & $20-100$ & $200-300$ \\
III & unstable & $200-500$ & $100-200$ & $300-500$ \\
IV & very unstable & over 500 & over 200 & over 500 \\
\hline
\end{tabular}

Table 2. Parameters of seismic waves of dynamic phenomena

\begin{tabular}{lcccccc}
\hline $\begin{array}{l}\text { Energy of dynamic } \\
\text { phenomenon, J }\end{array}$ & $\begin{array}{c}\text { Vibration } \\
\text { velocity, } \\
10^{-4}, \mathrm{~m} / \mathrm{s}\end{array}$ & $\begin{array}{c}\text { Coefficient } \\
\text { of variation }\end{array}$ & $\begin{array}{c}\text { Average } \\
\text { amplitude of } \\
\text { vibrations, } 10^{-7}, \mathrm{~m}\end{array}$ & $\begin{array}{c}\text { Line } \\
\text { frequency, } \\
\text { Hz }\end{array}$ & $\begin{array}{c}\text { Wave } \\
\text { length, m }\end{array}$ & $\begin{array}{c}\text { Duration of } \\
\text { vibrations, s }\end{array}$ \\
\hline$(1.8-5.6) \times 10^{2}$ & 0.75 & 0.23 & 3.0 & $50-40$ & $120-160$ & $1.0-1.5$ \\
$5.6 \times 10^{2}-1.8 \times 10^{3}$ & 1.26 & 0.20 & 5.1 & $40-30$ & $160-200$ & $1.5-2.0$ \\
$(1.8-5.6) \times 10^{3}$ & 2.26 & 0.18 & 14.4 & $30-25$ & $300-350$ & $2.0-3.0$ \\
$5.6 \times 10^{3}-1.8 \times 10^{4}$ & 3.32 & 0.10 & 21.1 & $25-20$ & $350-400$ & $3.0-4.0$ \\
$(1.8-5.6) \times 10^{4}$ & 6.16 & 0.28 & 56.1 & $20-18$ & $400-450$ & $4.0-5.0$ \\
$5.6 \times 10^{4}-1.8 \times 10^{5}$ & 11.16 & 0.08 & 101.6 & $18-15$ & $450-500$ & $5.0-6.0$ \\
$(1.8-5.6) \times 10^{5}$ & 13.02 & 0.14 & 165.9 & $15-13$ & $500-550$ & $6.0-7.0$ \\
$5.6 \times 10^{5}-1.8 \times 10^{6}$ & 14.56 & 0.13 & 185.5 & $13-10$ & $550-600$ & $7.0-8.0$ \\
$(1.8-5.6) \times 10^{6}$ & 17.35 & 0.07 & 368.4 & $10-8$ & $600-700$ & $8.0-10.0$ \\
$5.6 \times 10^{6}-1.8 \times 10^{7}$ & 22.15 & 0.11 & 470.3 & $8-5$ & $700-800$ & $10.0-12.0$ \\
$1.8 \times 10^{7}$ & 22.15 & - & 881.8 & $5-3$ & 800 & 12.0 \\
\hline
\end{tabular}


basin mines. The value of that criterion characterizes stable/unstable state of rocks outcropping. At $\mathrm{K}<0.25$ the rocks containing workings are stable, at $\mathrm{K}=0.25,0.4$ - average, at $\mathrm{K}=0.4,0.65$ - unstable. A similar approach is used in typical passports of mine workings barring/ supports for non-ferrous metallurgy mines [9].

Improvement of that criterion is in the accounting for the concentration of stress from workings and structural weakness of rock mass by inputting numerical factors in the criterion:

Table 3. Energy classification of dynamic effects

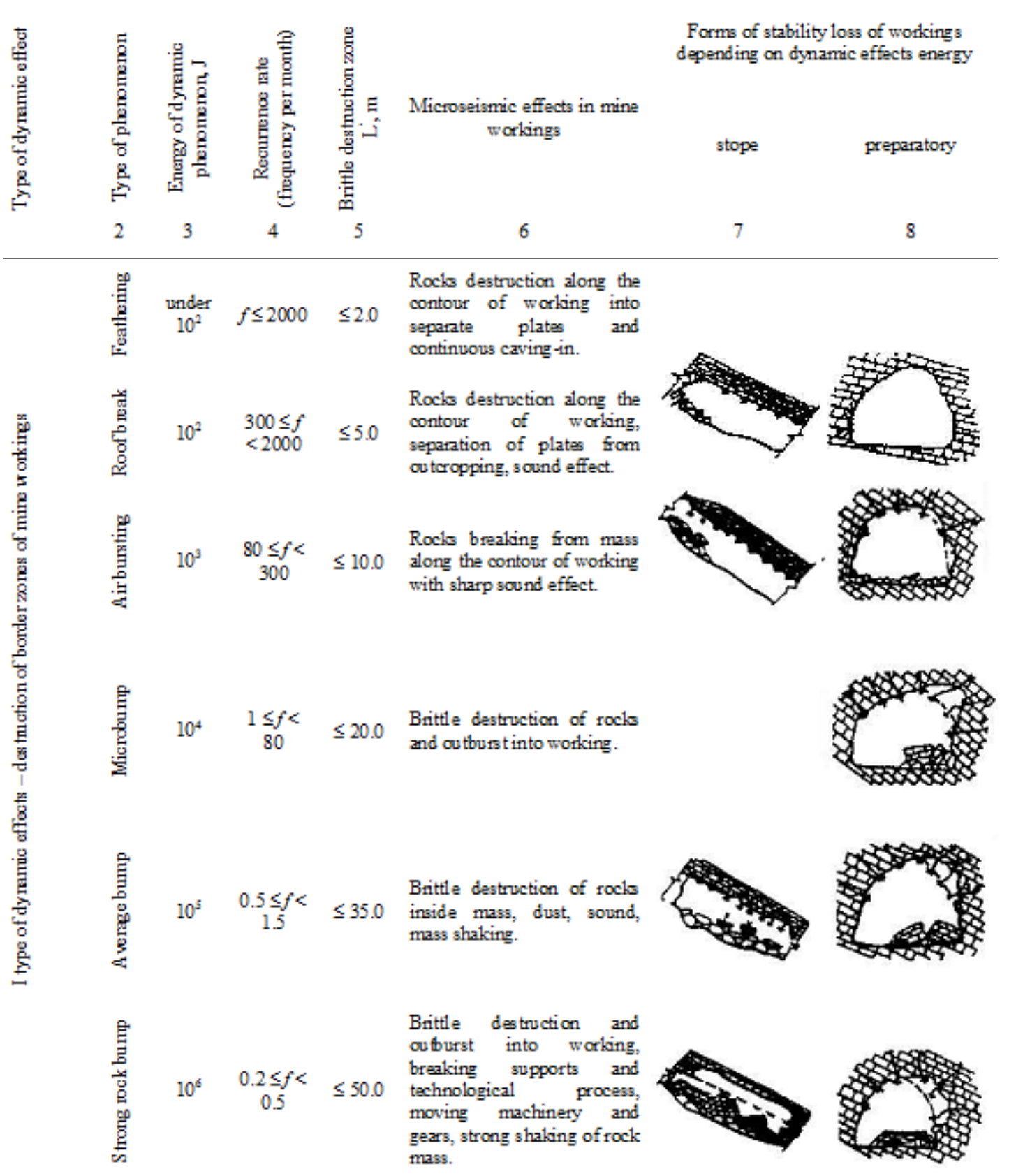




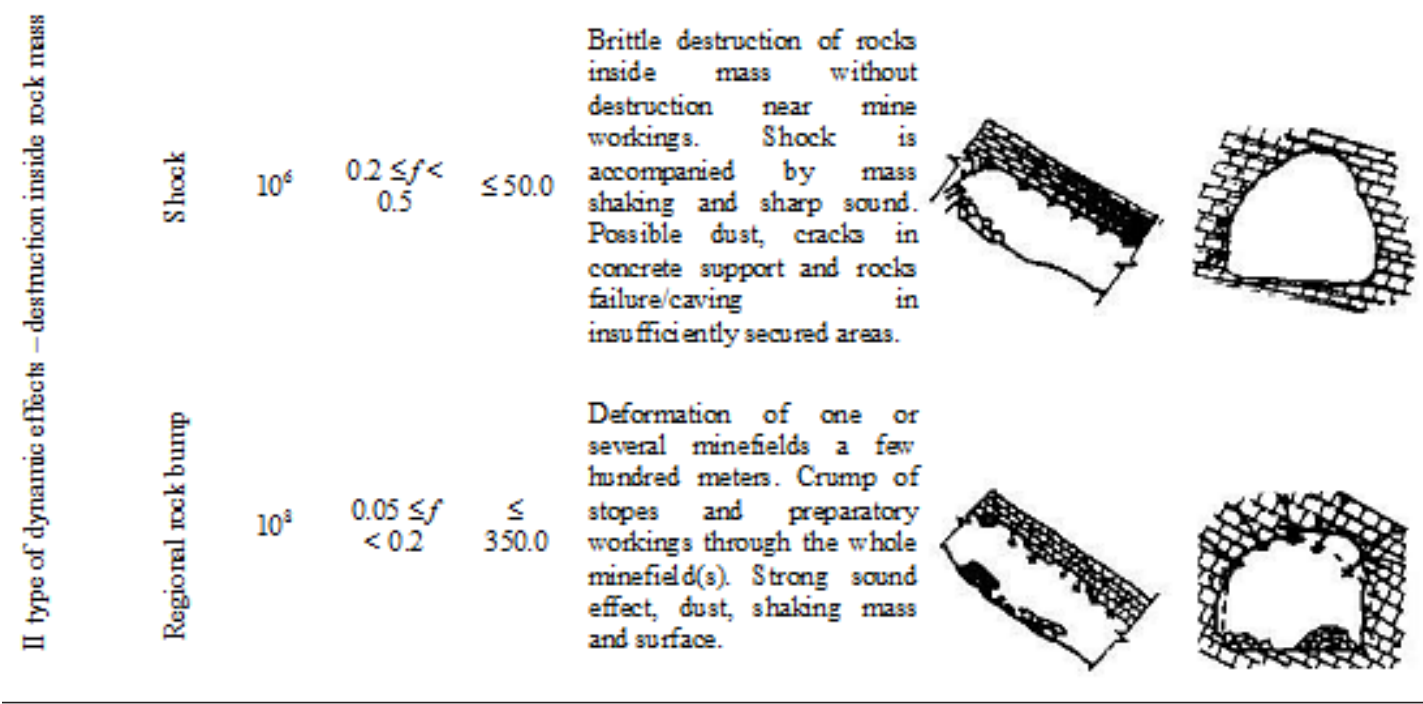

Table 4. State of workings and rocks categories by stability

\begin{tabular}{|c|c|c|c|c|c|c|c|c|c|}
\hline \multirow[t]{2}{*}{ Mine } & \multirow[t]{2}{*}{$\begin{array}{c}\text { Total } \\
\text { workings }\end{array}$} & \multirow[t]{2}{*}{$\begin{array}{c}\text { Sites } \\
\text { surveyed }\end{array}$} & \multicolumn{3}{|c|}{$\begin{array}{c}\text { Number of workings' } \\
\text { sites by operating } \\
\text { condition }\end{array}$} & \multicolumn{4}{|c|}{$\begin{array}{l}\text { Category of } \\
\text { rocks stability }\end{array}$} \\
\hline & & & stable & satisfactory & unstable & I & II & III & IV \\
\hline Cheryomukhovskaya & a 34 & 72 & 56 & 13 & 3 & 13 & 21 & 31 & 7 \\
\hline $14-14^{\text {bis }}$ & 40 & 102 & 35 & 61 & 6 & - & 6 & 50 & 35 \\
\hline Kalyinskaya & 30 & 67 & 46 & 21 & - & - & 19 & 45 & 3 \\
\hline
\end{tabular}

Table 5. Dependency of workings stability on seismic activity of rock mass (mine $14-14^{\text {bis }}$ )

\begin{tabular}{lcccc}
\hline \multirow{2}{*}{ Workings } & Total workings & \multicolumn{3}{c}{ Number of workings at } \\
condition & surveyed & low seismic activity & middle & high \\
\hline Stable & 31 & 22 & 6 & 3 \\
Satisfactory & 65 & 19 & 20 & 26 \\
Unstable & 6 & - & - & 6 \\
\hline
\end{tabular}

$$
K \gamma H \leq \xi K_{c} R_{c s}
$$

where $\mathrm{K}$ - coefficient of stress concentration caused by developing a mine working; $x$ and $\mathrm{K}_{\mathrm{n}}$ - are coefficients of structural weakness and lasting strength of rock mass; $\mathrm{R}_{\mathrm{cs}}-$ ultimate uniaxial compression strength of rocks in sample [10].

Condition (4) suggests the loss of mine working's stability immediately upon reaching the critical point ÊgH $=\mathrm{xK}_{\mathrm{n}} \mathrm{R}_{\mathrm{c}}$.

Meantime, as the practice shows, noncompliance with condition (4) tells only that destruction will take place but its nature/size cannot be found.

Thus the existing approaches to the assessment and classification of rocks outcropping require further development as they do not give quantity assessment of destruction at all the stages of rock mass deformation near mine workings, do 
not account for the mechanics of rocks after dynamic effects and do not ensure control over rock mass mechanics at before- and over-limit stages of deformation.

\section{RESULTS}

The analysis of mine workings stability during dynamic forms of rock pressure showed that dynamic effects emerge in the circumstances when the velocity of growth of stress in ultimatestress parts of rock mass adjacent to a mine working exceeds the maximal velocity of stress relaxation in it [11-12].

Rock bumps emerge upon certain combination of mining geological and mining engineering conditions. They are rather diverse and related to many factors which determine not only the emergence of rock bumps but their strength and nature and effect on mine workings.

For the conditions of OAO Sevuralboksitruda, developing bauxite deposits over 1,000 m deep, high non-uniform tectonic stress field development is typical. Meantime, some areas of the rock mass are transferring into limit and overlimit state, accumulating potential energy released in the form of brittle dynamic destruction of the rock mass in the course of mining. The geodynamics of those processes are not sufficiently studied, so the reasoning of the method of geodynamic stability of mine workings in the circumstances of rock pressure dynamic effects as
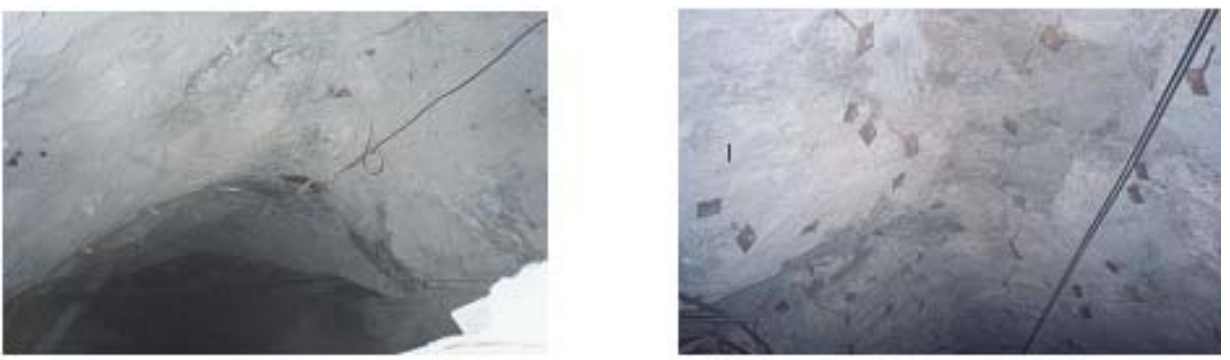

Fig. 2. Play upon beams (mine $14-14^{\text {bis }}$, roadway, horizon $-620 \mathrm{~m}$ )

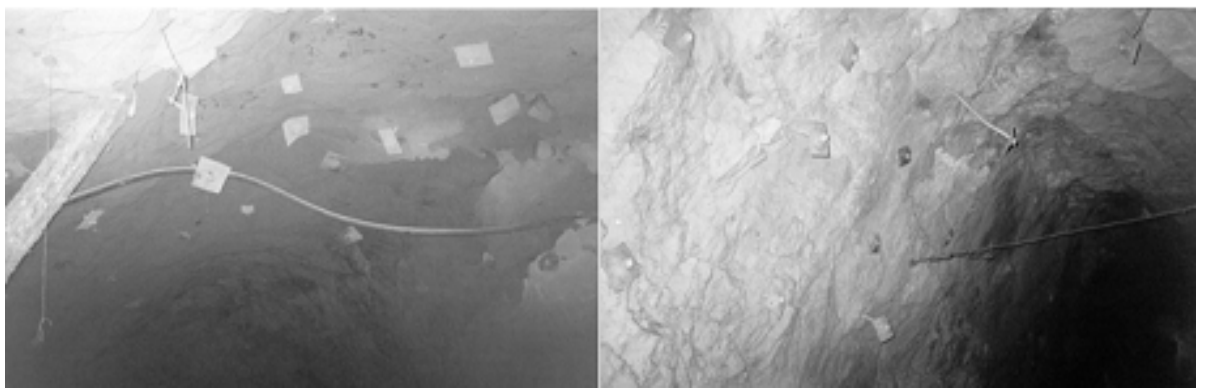

Fig. 3. Play upon beams (mine $14-14^{\text {bis }}$, roadway, horizon $-680 \mathrm{~m}$ )
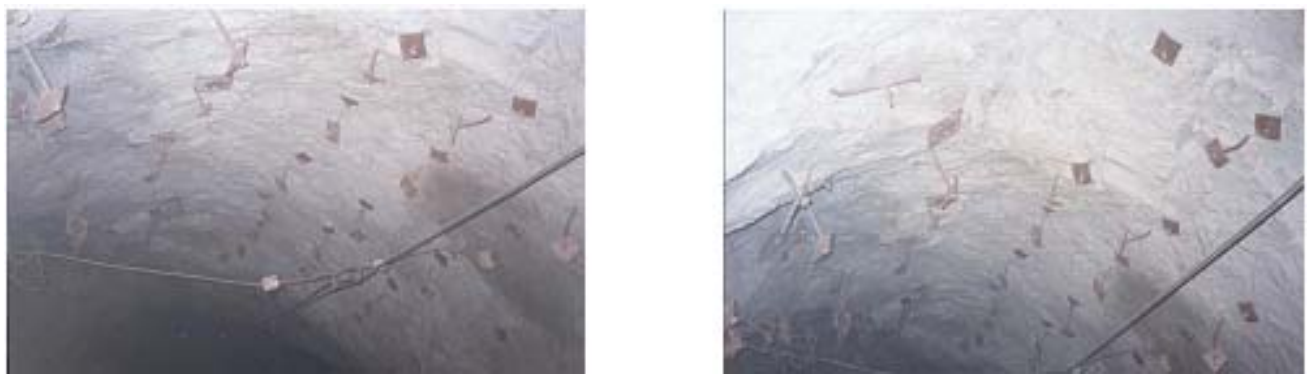

Fig. 4. Play upon beams (mine $14-14^{\text {bis }}$, loading crosscut, horizon $-740 \mathrm{~m}$ ) 
well as the development of efficient barring/ support methods is rather urgent.

For field research of dynamic waves effect on mine workings of OAO Sevuralboksitruda, the two methods were used: - Visual assessment of mine workings stability;

- Regional prognostication of seismic activity of rock mass according to the seismic measurements data by Severouralsk seismic station.

Specialists of the National Mineral Resources University (the Mining University) and OAO Sevuralboksitruda did a survey of mine workings in compliance with the University's methodology to find the compliance of types/ parameters of supports with mining geological and mining engineering conditions. The visual survey methodology included a questionnaire to assess the stability of mine workings of OAO Sevuralboksitruda's mines.

The condition of each working's site was fixed in the questionnaire by a number of parameters and assessed by stability category as stable, limit, unstable and very unstable.

Upon the questionnaire's results, the consolidated classification of mine workings in OAO Sevuralboksitruda's mines was made. Rock outcropping forms for various types and energies of dynamic phenomena were found [13-14].

The regional prognostication was made according to seismic instrumental measurements of Severouralsk seismic station in continuous mode. The structure of observation network was selected accounting for mining development, actual sensitivity of the equipment used and ensured stable registration of seismic phenomena with energies at least $100 \mathrm{~J}$ with the following errors: source coordinates - 20-30 m; seismic energy - \pm 0.5 of the order.

It was experimentally found that the nature of rocks destruction in near-contour area depends on the parameters of seismic waves which in turn are determined by the energy of dynamic phenomena (Table 2).

During dynamic effects, vibrations begin in immediate rock roof of preparatory workings and stopes, roof vibration amplitudes are more than an order of magnitude higher than the amplitude of seismic waves and in some cases it causes uncontrolled caving of rock roof which allows to conclude on resonance phenomena emergence during vibrations of deck rocks. It is also acknowledged by the frequency range coalescence of immediate roof hardband area's free vibrations and seismic waves $(\mathrm{f}=3-50 \mathrm{~Hz})[10,15]$.

From the point of rocks stability assessment in dynamic manifestation of rock pressure, it is the most important thing to account for the type of dynamic phenomenon, i.e., the specifics of destruction, energy range, frequency and length of seismic waves vibrations.

The specialists of the Mining University worked out an energy classification of dynamic phenomena which most fully discloses the nature of dynamic phenomena effects on mine workings (Table 3).

The first type of dynamic effects is characterized by seismic waves advance in the form of stretching from the source to all directions. In that case, seismometers of mine's network of observations register the first semi-wave arrival stretching while the coordinates of dynamic effect's origin coincide with the center of rock mass destruction ellipse. Mass destruction area spreads from the source.

The second type of dynamic effect (mining and tectonic) is characterized by quadrant advance of seismic waves from the source; mine network's seismometers register advance semiwave - stretching in one direction and compression in the other.

Based on the results of three months' observations, current monthly maps of seismic activity were made with isolines of the number of phenomena modified to seismic energy $10^{2.5} \mathrm{~J}$. Seismic activity maps combined with mining plan permitted to classify as bump hazardous objects the workings which fell into the area limited by isoline. The higher the isoline, the higher the rock bump energy. Seismic activity isoline $-m_{i}=1$, was found from the equation:

$$
\mathrm{m}_{\mathrm{i}}=10^{\gamma\left(\mathrm{K}_{\mathrm{i}}-\mathrm{K}_{\mathrm{o}}\right)}
$$

where $g$ - angular factor of seismic effects recurrence rate graph; $K_{i}$ - energy class of the i-th seismic phenomenon; $K_{0}$ - the lowest informative energy class of a seismic phenomenon (for OAO Sevuralboksitruda $=2.5$ ). 
The analysis of regional prognostication of bump hazards in mines showed that in the range of isolines from 1 to $10-20$, within a predicted time some insignificant seismic phenomena emerge. Therefore, special attention was paid to the analysis of the number of dynamic phenomena emerging in the intervals between isolines from 1 to 5 , from 5 to 10 , from 10 to 15 and from 15 to 20 within rather long periods.

To study the probability of the regional prognostication for dynamic phenomena with various energies, the graphs shown on Figure 1 were built.

As seen from those graphs, the most exact prognostications relate to dynamic phenomena with seismic energy of $10^{5} \mathrm{~J}(1 \AA+5)$ [16-17].

\section{DISCUSSION}

During processing of questionnaires for each working site, stress criteria $\mathrm{C}_{\mathrm{s}}$ were calculated [18-19].

Maintenance state of workings was determined and their correlations were found.

Comparative data on the state of workings of OAO Sevuralboksitruda studied and stability of rocks outcropping by $\mathrm{C}_{\mathrm{s}}$ criteria are represented in Table 4. rocks relate to I and II categories by stability. In mine $14-14^{\text {bis }}$ such rocks are $6 \%$ only, so the portion of workings with undamaged supports decreased to $34 \%$. In mine $14-14^{\text {bis, }} 34 \%$ of sites by $C_{s}$ criterion are classified as IV category of stability, 49\% - II category [20].

In Cheryomukhovaya mine, workings of horizons $-427,-500,-560,-620$ m were surveyed. Almost all the sites surveyed are secured using single support type - ferroconcrete beams at $10 \tilde{1}$ $\mathrm{m}$ grid. Thus, the differences in workings stability are related not to the strengthening effect of support which may be deemed the same but to the effect of mining geological and mining engineering conditions. Among the decisive factors for workings' condition, mine specialists noted fracturing of rock mass, effect of extraction and explosions in productive workings.

In mine 14-14 ${ }^{\text {bis }}$ deeper horizon workings were put into questionnaire: mainly, $-740 \mathrm{~m}$, less 680 and $-620 \mathrm{~m}$. (see Figure 2, 3 and 4). Out of them, $60 \%$ of workings are within the effect of the excavation zone while more than half of sites surveyed are in the areas with seismic activity of geological blocks. Mine working's stability related to the level of blocks' seismic activity may be assessed from Table 5 showing the distribution of the sites surveyed by the level of seismic activity and workings stability.

The questionnaires noted great effect of explosion waves on the condition of workings, especially from wells explosion in horizon and single stalls mining. Out of 9 workings, located near the ore body, 6 were satisfactory and 3 were unstable.

For mine $14-14^{\text {bis }}$ rather high portion of III and IV stability category rocks is typical. Meantime, many workings (loading crosscut to the $3^{\text {rd }}$ horizon $-680 \mathrm{~m}$ and others) are assessed as stable. The same situation is in Kalyinskaya mine workings. Out of 67 sites surveyed, 57 are in the excavation works zone.

As a result, in $70 \%$ cases relate to III and IV category of stability by $\mathrm{C}_{\mathrm{s}}$ criterion while $68 \%$ of workings are in stable condition.

\section{CONCLUSION}

The practically obtained information on operation condition of mine workings using methodology of visual assessment of mine workings stability and regional prognostication of seismic activity of rock mass according to seismic instrumentational measurements allowed to find the shapes of rock outcropping irregularities at various kinds and energies of dynamic phenomena and improve and give more exact assessment of stress criterion.

The practical experience of geodynamic stability assessment of mine workings using improved stress criterion allowed to cut the costs on supports of preparatory and permanent mine workings and to improve mining safety.

The data so obtained may be used by enterprises/organizations engaged in design, construction and maintenance of underground mine workings in mines exposed to rock bumps, and the information contained in this paper may be of some use for education, science and engineering staff dealing with barring and maintenance of mine workings in bump hazardous rocks of ore deposits.

The prospects of further scientific 
research in that field are the development and feasibility research of rational structures of seismic-resistant mine workings supports during the deep mining of bump hazardous deposits.

\section{REFERENCES}

1. Construction Rules and Regulations SNiP-9480. Underground Mine Workings. (1981). Moscow: Stroyizdat.

2. Andreyev, N.A. (1989). Effect of Rock Mass Destressing with Slots with Deep Shaft Maintenance. In Collection of Scientific Works of All-Russian Research Institute of Mining Geomechanics and Survey: Mine Geomechanics Issues in Development of Mineral Wealth (pp. 53-57). Leningrad.

3. Gelashvili, G.M. (1991). Preliminary Assessment of Potential Bump Hazard of Coal and Rocks. In Collection of Scientific Works of All-Russian Research Institute of Mining Geomechanics and Survey: Properties of Rock Mass and Controlling Its State (pp. 34-38). Saint Petersburg.

4. Zapryagayev, A.P. (1987). Research of Deformation Dependency of Rock Ore and Coal Mass during Destressing. In Collection of Scientific Works of All-Russian Research Institute of Mining Geomechanics and Survey: Controlling Bump Hazard of Rock Mass (pp. 71-75). Leningrad.

5. Baklashov, I.V., \& Kartoziya, B.A. (1984). Mechanics of Underground Structures and Support Design. Moscow: Nedra.

6. Bulychyov, N.S. (1994). Mechanics of Underground Structures. Moscow: Nedra.

7. Bulychyov, N.S., Amusin, B.Z., \& Olovyannyi, A.G. (1974). Design of Supports for Permanent Mine Workings. Moscow: Nedra.

8. Zaslavskiy, Yu.Z., Zorin, A.N., \& Chernyak, I.L. (1972). Designing Support Parameters of Deep Mine Workings. Kiev: Tekhnika.

9. Typical Passports of Mine Working Supports for Non-Ferrous Metallurgy Mines. (1976). Moscow: Ministry of Non-Ferrous Metallurgy of the USSR.

10. Trushko, V.L., Protosenya, A.G., Matveyev, P.F., \& Sovmen, Kh.M. (2000). Geomechanics of Rock Masses and Dynamics of Deep Mine
Workings. Saint Petersburg: Saint Petersburg Mining Institute.

11. Aksyonov, A.A. (1999). Assessment of Bump Hazard of Minefields Areas. A Report on Scientific and Research Work. Yekaterinburg.

12. Trushko, V.L. (2000). Assessment and Prognostication of Geodynamic Phenomena in Development of Solid Mineral Wealth. A Report on Scientific and Research Work. Saint Petersburg.

13. Trushko, O.V. (2006). Assessment of Stability of Mine Workings in Bump Hazardous Deposits. In $2^{\text {nd }}$ International Northern Socio-Ecological Congress. Papers of $4^{\text {th }}$ Interregional Scientific and Practical Conference "Exploration of Mineral Wealth of the North: Problems and Solutions” (pp. 60-65). Vorkuta.

14. Stavrogin, A.N., \& Protosenya, A.G. (1985). Strength of Rocks and Stability of Deep Mine Workings. Moscow: Nedra.

15. Batugina, I.M., \& Petukhov, I.M. (1988). Geodynamical Zoning of Deposits during Design and Operation of Mines. Moscow: Nedra.

16. Budnik, V.V. (1988). Control over Coal Seam under Stress via In-Seam Seismic Survey. In Collection of Scientific Works of All-Russian Research Institute of Mining Geomechanics and Survey: Mine Bumps. Mine Geology and Geophysics (pp. 27-32). Leningrad.

17. Timofeyev, V.L., \& Trushko V.L. (1984). Prognostication and Ensuring Stability of Horizontal Workings of Sevuralboksitruda's Deep Mines. In Interacademic Bulletin. Interaction of Supports and Rocks in Complex Environment (pp. 13-18). Leningrad: Leningrad Mining University.

18. Trushko, V.L., Timofeyev, O.V., \& Mikulin, Ye.I. (2003). Instruction for Choosing Type and Parameters of Supports for Permanent and Preparatory Mine Workings of North-Urals Basin Mines. Saint Petersburg.

19. Trushko, V.L., Ogorodnikov, Yu.N., Mikulin, Ye.I., Shirokov, A.V., \& Lokhnev, A.S. (2010). Instruction for Choosing Supports for Preparatory and Permanent Mine Workings of OAO “Sevuralboksitruda” mines. Severouralsk.

20. Trushko, O.V. (2015, April). Ensuring Sustainability of Preparatory and Permanent Mining Workings in Deep Mines of BumpHazardous Deposits. BBRA - Biosciences, Biotechnology Research Asia, 1(12), 695-703. 